\title{
The African herbal plants research and development amid COVID-19
}

\author{
Force Tefo Thema
}

1 $\mathrm{n}$ the past eight years our research was primarily focused on green nano chemistry, biomimicry, nanomaterials and bio-conjugation/natural compounds. We were specifically using bottom to up approach techniques because it was untoxic. The fabrication and synthesis of nanomaterials via the green path (plant extract, bacteria, fungus) was an ideal strategy as much emphasis was on the biological compatibility and environment friendliness of the nanoparticles. Secondly, more attention was on time frames and financial considerations of other physical and chemical techniques that were expensive and toxic to employ.

Having noted the above and the recent outbreak of the COVID-19 pandemic we found ourselves in a rapidly growing emerging research trend. This new trend, substantiated and confirmed by the current approach of our research, is more on the traditional herbal plants abundant in Africa. There are so many herbal plants in Africa, which are medicinal species and have been used over the years by the African Traditional Doctors (ATDs) to treat and cure various ailments. Likewise, as scientific researchers, we have now made significant strides on synthesizing of nanomaterials fabricated from the extract of these herbal medicinal plants. There are some research initiatives that show this emerging trend and published in peer reviewed journals in the year 2020.

The above indicate the recent emerging trends on nanomaterials, which have shown antibacterial activity against gram negative and gram-positive bacteria. Moreover, the introduction of the new intense approach of antibacterial, inflammatory and antiviral nanomaterials synthesized via herbal plants extract is unavoidable especially during the current wake of COVID-19.

It is worth noting that there was a symposium which was recently held by the Ministry of Health and Wellness Symposium. This symposium was in Commemoration of the African Traditional Medicine Day in the Republic of Botswana under the theme "Integration of Traditional Medicine in Curricula of Health Sciences students in Universities in the African region". This symposium signifies the importance and the strides taken to justify the emerging research trends. The new trends encourage collaboration between scientists and the traditional doctors. The said symposium was held as a deliberate effort to appreciate the immeasurable knowledge on medicinal herbal plants by the African Traditional Doctors (ATDs).
Being cognizant of the above, the emerging research trend now sees the scientific community to engage with the ATDs in the herbal medicine space, especially, during the COVID-19 era. The issues of herbal medicine packaging and concentrations (i.e. dose) are the most critical highlights addressed. Though there have been instances where ATDs had much knowledge on herbal medicine, it has been proven that there are cases were patients were over dozed resulting into serious side effects and ultimate deaths.

In conclusion, this commentary is based on the robust track records of the UNESCO-Unisa Africa Chair in Nanoscience and Nanotechnology (U2ACN2) iThemba-LABS/National Research Fund research Fellows in the biosynthesized metallic oxides nanoparticles using a large variety of natural extracts and their medical applications as reported in several international ISISClpublications ${ }^{[1]}$.

\section{Reference}

[1] Thema, F. T., Letsholathebe, D., Mphale, K. 2020. Enhanced antibacterial properties of green synthesized nano ceria via Agathosma betulina natural extract. Materials Today: Proceedings, https://doi.org/10.1016/j.matpr.2020.05.010

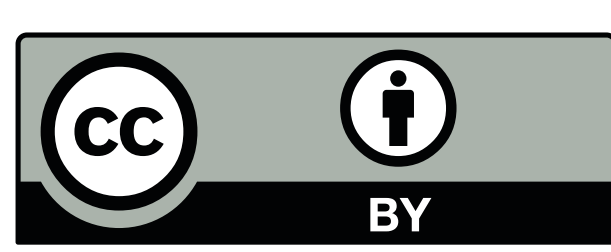

This article is an Open Access article distributed under the terms and conditions of the Creative Commons Attribution (CC BY) 4.0 International license (http://creativecommons.org/licenses/by/4.0/). 